\title{
Material Pore Size
}

National Cancer Institute

\section{Source}

National Cancer Institute. Material Pore Size. NCI Thesaurus. Code C112332.

A quantitative or qualitative measurement of the physical dimensions of the pores in a material. 